\title{
Geometry Modification of Helical Gear for Reduction of Static Transmission Error
}

\author{
Jeonghyun Park ${ }^{1}$ Changjun Seo ${ }^{2}$, Kwangsuck Boo² and Heungseob Kim², \\ ${ }^{1}$ Graduate school of Mechanical Engineering, Inje University, 50834 Gimhae, Gyoungnam, Korea \\ ${ }^{2}$ HSV-TRC Center, Inje University, 50834, Gimhae, Gyoungnam, Korea
}

\begin{abstract}
Gear systems are extensively employed in mechanical systems since they allow the transfer of power with a variety of gear ratios. So gears cause the inherent deflections and deformations due to the high pressure which occurs between the meshing teeth when transmit power and results in the transmission error. It is usually assumed that the transmission error and variation of the gear mesh stiffness are the dominant excitation mechanisms. Predicting the static transmission error is a necessary condition to reduce noise radiated from the gear systems. This paper aims to investigate the effect of tooth profile modifications on the transmission error of helical gear. The contact stress analysis was implemented for different roll positions to find out the most critical roll angle in view point of root flank stress. The PPTE (peak-to-peak of transmission error) is estimated at the roll angles by different loading conditions with two dimensional FEM. The optimal profile modification from the root to the tip is proposed.
\end{abstract}

\section{Introduction}

Gear system is being widely used for the rotational speed reduction and acceleration as well as converting the operational direction. Tooth deflection and bending stress in root are generated when a pair of gear is meshing. It causes radiated noise from the gear case by transmission error which excites driving shafts and bearings mounted on them.

Akerblom [1] and Smith [2] found the correlation of noise induced by excitation of transmission error in the entire system. Smith studied about reducing gear transmission error according to contact ratio changes. Park [3] and Perret-Liaudet [4] classified transmission error into static transmission error (STE) and dynamic transmission error (DTE). Many traditional scientists studied method to reduce transmission error in gear system. MarkoviĆ and FranuloviĆ [5] studied on adjust of contact ratio of gear and Rigaud and Barday [6] implemented study on reduction of transmission error by modifying geometry of gear. In addition, Paul and Bhole [7] researched on reduction of transmission error by minimizing the contact stress at the end of tooth flank. Sivakumar [8] researched load transmission in high contact ratio gear system and Sawalhi Nader [9] studied about simulation method in rotation bearing fault phenomenon by rotation shaft vibration. Endo Hiroaki and Sawalhi Nader [9] studied about bearing vibration measurement simulation model at rotating gears. In this paper gear simulator was designed to measure rotation

${ }^{1}$ Corresponding author : mechhsk@inje.ac.kr 
angle of pinion and gear and estimate transmission error via difference between both angles.

In this study, method on reduction of general helical gear was researched by finite element analysis. First of all, data of tooth tip deflection was collected in rotational situation of gear pair. Based on it, gear profile modification curve was decided. Finite element analysis model was generated by commercial software like as Hypermesh and Abaqus, to carry out finite element analysis in different loading torque conditions. Then, gear contact characteristics such as transmission error and bending stress was compared and analyzed.

In addition, characteristics analysis of transmission error along the loading torque was studied by experimental method. The test bench was set in order to measure transmission error, and frequency characteristics of transmission error was compared and analyzed in different three loading conditions.

\section{FEA for static transmission error}

\subsection{Helical gear design}

Target gear in Fig.1 was designed for diesel engine balance unit operating at maximum 450Nm. gear specification is shown as Table 1, and elastic modulus and poisson's ratio were applied as $208 \mathrm{GPa}$ and 0.3 . Each gear model consists of finite elements of 570 thousands.

Table 1. Helical gear design parameters for gear profile modificatio

\begin{tabular}{c|c}
\hline Description & Each gear \\
\hline Number of teeth & 43 \\
Module(mm) & 1.5 \\
Helix angle(deg) & 26 \\
Pressure angle(deg) & 15 \\
Pitch diameter(mm) & 71.8 \\
Face width(mm) & 12 \\
Addendum(mm) & 1.5 \\
Dedendum(mm) & 2.025 \\
\hline & \\
&
\end{tabular}

Figure 1. Helical gears for gear profile modification

\subsection{Finite Element Analysis conditions}

Finite element analysis conditions for model that its profile was modified is that rotational speed of driving gear was applied as shown in Fig. 2 and each loading torque, $450 \mathrm{Nm}, 1000 \mathrm{Nm}$, and $150 \mathrm{Nm}$, was applied to driven gear. Friction coefficient is 0.1 , and translational and rotational movement except for rotational axis were constrained to move. 


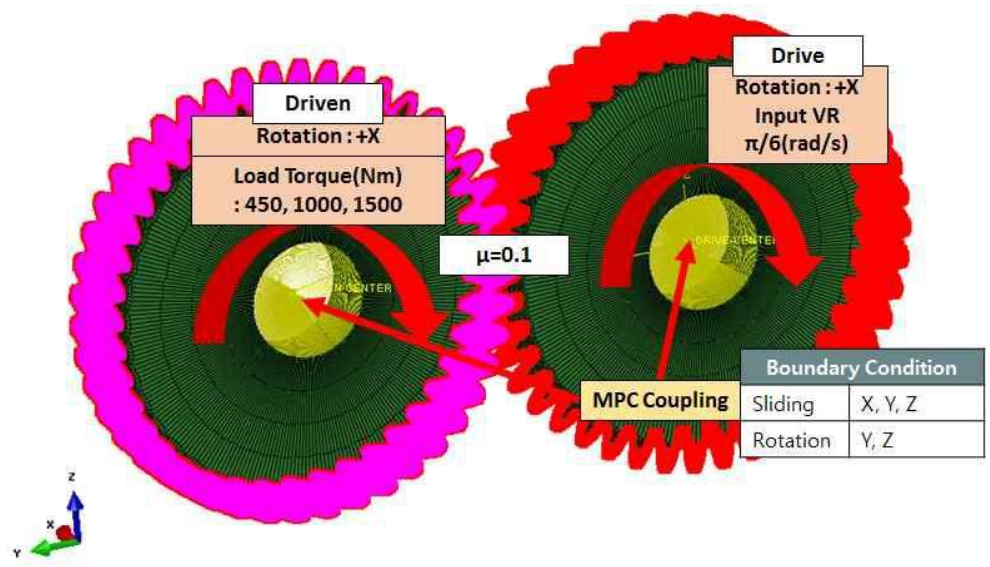

Figure 2. Boundary condition for gear profile modification

\section{Simulation for prediction of static transmission error}

\subsection{Transmission error reduction along the tooth profile modification}

Contact patterns varies along the contact ratio (CR) as gear pair is rotating. Contact ratio is calculated by Eq. (1), so this gear pair has approximately 3.7 contact ratio. Therefore, three or four teeth contact patterns are periodically shown Fig.3.

$$
\mathrm{CR}=\frac{\sqrt{\left(r_{1}+a\right)^{2}-r_{1}^{2} \cos ^{2} \alpha}}{\pi m \cos \alpha}+\frac{\sqrt{\left(r_{2}+a\right)^{2}-r_{2}^{2} \cos ^{2} \alpha}-\left(r_{1}+r_{2}\right) \sin \alpha}{\pi m \cos \alpha} \cong 3.7
$$

Where $r_{1}, r_{2}$ is pitch radius of pinion and gear, $\mathrm{a}$ is addendum width, $\alpha$ is pressure angle, and $\mathrm{m}$ is module. Paul and Bhole [7] researched on gear profile modification method by minimizing the contact stress at the end of tooth flank and they applied some relief at teeth tip. When gear pair rotates, deflection of $i^{\text {th }}$ tooth is maximum. When gear pair rotates, deflection of $i^{\text {th }}$ tooth is maximum. Then, deflection characteristics is not straight line but parabolic line until meshing finish, because $i+1 \sim 3$ th tooth mesh simultaneously. As a result, profile was modified as curve from tooth tip to root, $39.8 \mu \mathrm{m}$ and $38.4 \mu \mathrm{m}$ respectively. In this paper gear profile was modified as involute curve. Both side of a teeth has same profile curve.

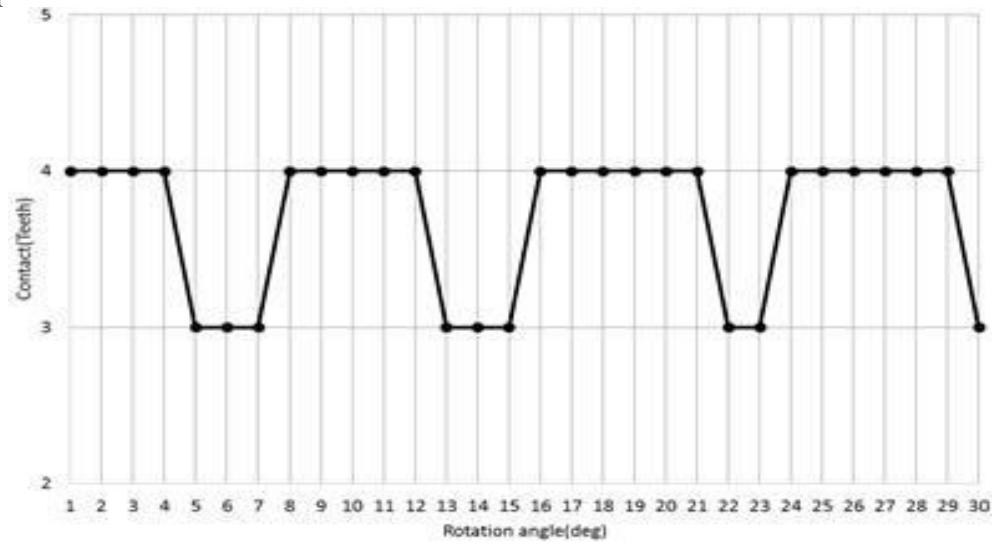

(a) Contact teeth number of rotation angle 


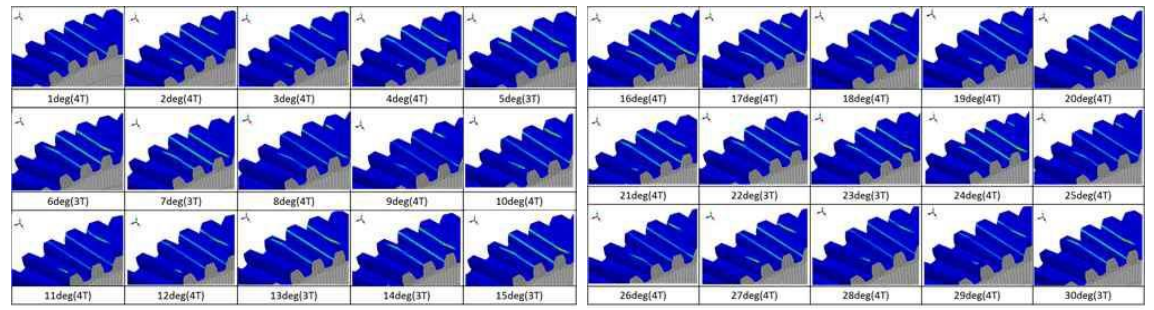

(b) Teeth contact of rotation angle

Figure 3. Contact pattern

Transmission error for teeth modification model was calculated by Eq. (2), and it was reduced to maximum $23.5 \%$ and minimum $13.2 \%$ via profile modification in Fig.4 and Table 2. The formulation means difference between drive gear and driven gear on slow rotation velocity as under 20RPM. In formula, thetas mean rotation angle(rad) and $\mathrm{R}$ means pitch radius. It is possible to reduce gear rotation vibration characteristics as transmission error by applying tip relief under teeth deflection propensity. Gear profile modification as tip relief that is about $40 \mu \mathrm{m}$ is in manufacture error region. So it is very important method to manufacture gear tooth.

$$
\text { Trans mission error }=\theta_{\text {gear }}-\frac{R_{\text {prion }}}{R_{\text {gear }}} \theta_{\text {piim }}
$$

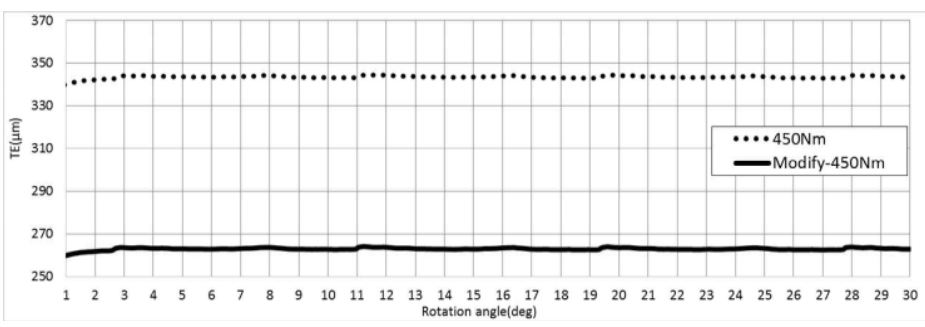

(a) Torque $450 \mathrm{Nm}$

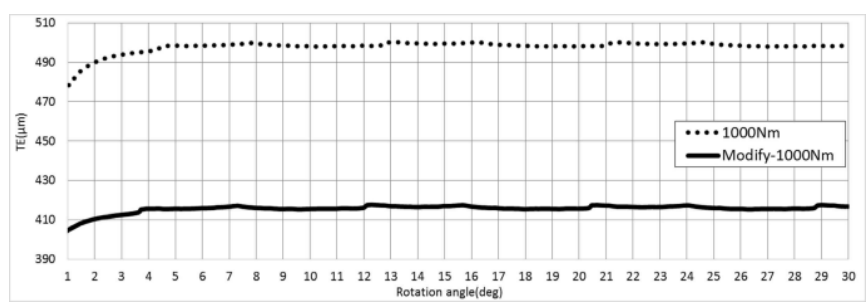

(b) Torque $1000 \mathrm{Nm}$

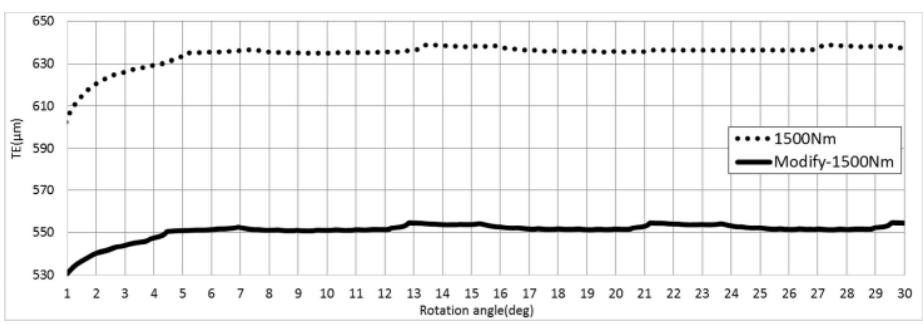

(c) Torque $1500 \mathrm{Nm}$

Figure 4. Transmission error via gear profile modification 
Table 2 Root stress of gear profile modification

\begin{tabular}{c|c|c}
\hline \multicolumn{2}{c|}{ Transmission error } & Root stress(MPa) \\
\hline \multirow{2}{*}{$450 \mathrm{Nm}$} & Original & 1276 \\
\cline { 2 - 3 } & Modify & 1194 \\
\hline \multirow{2}{*}{$1000 \mathrm{Nm}$} & Original & 2760 \\
\cline { 2 - 3 } & Modify & 2552 \\
\hline \multirow{2}{*}{$1500 \mathrm{Nm}$} & Original & 4032 \\
\cline { 2 - 3 } & Modify & 3262 \\
\hline
\end{tabular}

Load sharing was calculated at each rotational angle as shown Eq. (3). Contact force which is a target tooth flank versus total contact force on contact area was calculated for each rotational angle. It is found load sharing increased after teeth profile modification as shown Fig. 5. It has same definition as the above description for contact force dispersion. Particularly, when single tooth rotates, load sharing increased by $10 \sim 12 \%$ after $15 \sim 16$ degree rotation that contact force is maximum. It means that difference of contact force of contact tooth was reduced before maximum contact force occurred, and it can be also considered that many teeth rotated with stronger contact force than before modifying tooth profile. As shown below load sharing, this is because $i+1$ th tooth keeps up its meshing as soon as meshing of $\mathrm{i}^{\text {th }}$ tooth reached maximum through tooth profile modification.

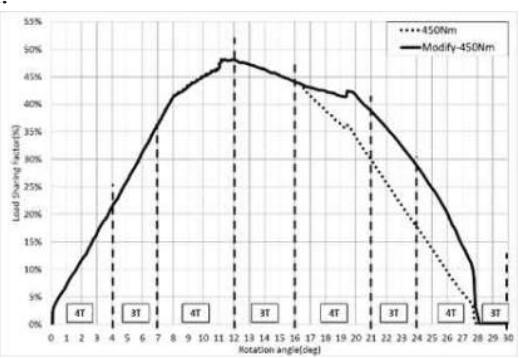

(a) Torque $450 \mathrm{Nm}$

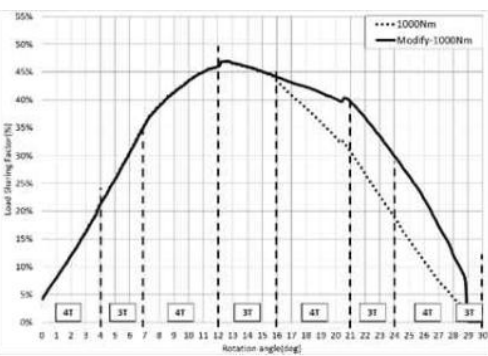

(b) Torque $1000 \mathrm{Nm}$

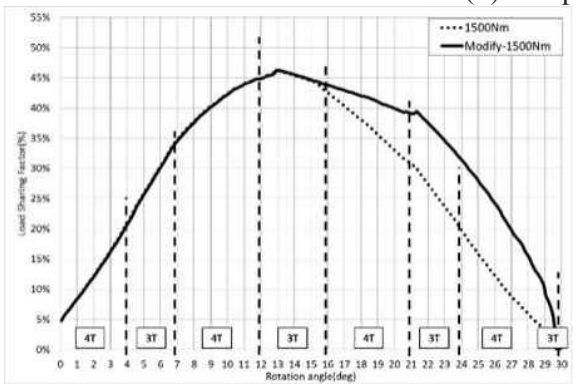

(c) Torque $1500 \mathrm{Nm}$

(dotted line : original, solid line : modified)

Figure 5. Load sharing improvement by profile modification

\section{Conclusion}

In this study, we found the method to reduce transmission error in gear system. Gear profile modification method was applied based on tooth deflection. It was found that this method has better load sharing effect on reduction of transmission error and bending stress of tooth in standard loading torque $(450 \mathrm{Nm})$ and higher loading conditions. Therefore, these results definitely show gear profile modification method is effective to reduce transmission error. In further study, 
application method on correlation between transmission error with shaft vibration and tip relief by tooth profile modification will be researched.

\section{Acknowledgement}

This research was supported by The Leading Human Resource Training Program of Regional Neo industry through the National Research Foundation of Korea (NRF) funded by the Ministry of Science, ICT and future Planning. (2016H1D5A1911140).

This research was supported by The Leading Human Resource Training Program of Regional Neo industry through the National Research Foundation of Korea (NRF) funded by the Ministry of Science, ICT and future Planning. (2016H1D5A1910490).

\section{References}

1. M. Akerblom, Volvo Construction Equipment Components ABSE-631 85(2001)

2. J. D. Smith, Gear Noise and Vibration, CRC Press, (2003)

3. J. I. Park, D. H. Cho, Trans. Korean Soc. Mech. Eng. A, 28(9), 1359(2004)

4. J. C. Perret-Liaudet, E. A. Rigaud, and B. Nelain, SAE2014-01-2090, (2014) 5. K. MarkoviĆ, M. FranuloviĆ, UDC 621.833.15:62-233.5, 19 (2011)

6. E. Rigaud, D. Barday, HAL-00121847, 1961 (1999)

7. I. D. Paul, G. P. Bhole, ICIEOM Spring conference, 197(2010)

8. M. Rameshkumar, G. Venkatesan, P. Sivakumar, AGMA Technical Resources, (2010)

9. Endo Hiroaki, Sawalhi Nader. Gearbox Simulation Models with Gear and Bearing Faults (2012) 